\title{
Behaviour of Carcinus maenas feeding on large Mytilus edulis. How do they assess the optimal diet?
}

\author{
C. Ameyaw-Akumfi ${ }^{*}$ \& R. N. Hughes ${ }^{* *}$ \\ School of Animal Biology, University College of North Wales, Bangor, Gwynedd LL57 2UW, United Kingdom
}

\begin{abstract}
Shore crabs Carcinus maenas (L.) of 60 to $70 \mathrm{~mm}$ carapace width attacked mussels Mytilus edulis $\mathrm{L}$. of 30 to $50 \mathrm{~mm}$ shell length by boring through the hinge or ventral umbonal region, but larger mussels could not be opened by this method. Within the 30 to $50 \mathrm{~mm}$ size range, crabs preferred smaller mussels and appeared to exercise their choice after handling prey of different sizes. When feeding on natural clumps of mussels, crabs consumed all encountered mussels small enough to be crushed $(<30 \mathrm{~mm})$ but also consumed some of the larger, less profitable mussels. This behaviour would result if the predator continually adjusts its estimate of prey availabilities according to the last few items handled.
\end{abstract}

\section{INTRODUCTION}

When feeding on mussels, crabs prefer smaller prey that can be crushed, so avoiding the much longer handling times associated with alternative opening techniques that must be used for larger mussels (Elner \& Hughes 1978). As a result, smaller mussels are selectively removed from natural populations (Seed 1969, Dare \& Edwards 1981) and the preferred sizes of prey often become depleted. Crabs therefore should benefit from having an efficient but flexible foraging behaviour that enables them to exploit larger prey when the preferred smaller sizes are scarce.

Mussels beyond the maximum size for crushing are opened by one of 2 methods (Elner 1978, Cunningham \& Hughes 1984): first, chipping the posterior edges of the valves, by chewing them with the mandibles, until a cheliped can be inserted to sever the large adductor muscle; second, forcing the propus of the cheliped through the ligament or through the ventral umbonal region, then twisting and prising the valves apart.

The present paper describes experiments assessing the readiness of crabs to attack mussels beyond the maximum size threshold for crushing and to select sizes

\footnotetext{
- Present address: Department of Zoology, University of Cape Coast, Cape Coast, Ghana

- Addressee for reprint requests
}

within this range. The effect of mussel aggregations on foraging behaviour is also considered.

\section{METHODS}

Mussels Mytilus edulis L. of 25 to $60 \mathrm{~mm}$ shell length (SL) and shore crabs Carcinus maenas (L.) of 60 to $70 \mathrm{~mm}$ carapace width $(\mathrm{CW})$ were collected from the Menai Strait, North Wales, U.K., after it had been established from the literature (Elner 1978, Cunningham \& Hughes 1984) that for crabs of $60 \mathrm{~mm} \mathrm{CW}$ the maximum size of mussel that can be crushed is about $30 \mathrm{~mm} \mathrm{SL}$. During experiments, crabs were placed individually in $60 \times 40 \times 20 \mathrm{~cm}$ plastic aquaria filled with aerated seawater at about $15^{\circ} \mathrm{C}$. To reduce visual disturbance of the crabs, their eyes were coated with red nail varnish. Vision is thought not to be used by $C$. maenas to feed on mussels (Elner \& Hughes 1978). Foraging behaviour was observed directly, but in the experiments with clumped prey, video recording was also used. Handling behaviour was observed directly and from video recordings made of over 100 attacks occurring both during the experiments (below) and during preliminary feeding trials.

Size selection among large mussels was ascertained for a batch of 20 crabs of $60 \mathrm{~mm} \mathrm{CW}$. Crabs were starved for $1 \mathrm{wk}$, to standardize hunger levels, then 
presented with a pair of mussels of 35 and $45 \mathrm{~mm}$ SL each day for $1 \mathrm{wk}$, with mussels being replaced as eaten. This daily ration would keep the crabs in a state of semi-starvation (Jubb et al. 1983). The numbers and sizes of mussels eaten were recorded. The same procedure was applied to a second batch of 65 to $70 \mathrm{~mm}$ crabs, using mussels of 45 and $55 \mathrm{~mm}$ SL.

The effect of clumping on feeding behaviour was examined using artificial groups and natural clumps of mussels. Artificial groups were made by placing 4 to 6 mussels of 10 to $60 \mathrm{~mm} \mathrm{SL}$ on the floor of the aquarium with their umbones converging to a common centre. This simple configuration allowed all encounters to be seen, a task otherwise made impossible by the complexity of natural clumps of mussels. Starved crabs were each presented with a group of mussels and observed by video recording for 6 to $10 \mathrm{~h}$. Recording times during $24 \mathrm{~h}$ were not standardized and it is possible that unsynchronized endogenous rhythms (Naylor 1958) may have contributed to differences in feeding rates among crabs. Encounters with individual mussels and prey selection were noted. Natural clumps of mussels were collected from the shore. Each clump contained about 100 mussels of 10 to $60 \mathrm{~mm} \mathrm{SL}$. A clump was presented to each of 25 starved crabs and video recordings were made of their activities during 6 to $10 \mathrm{~h}$ periods over several days.

To investigate the likelihood of crabs encountering large (>30 mm SL) and small mussels ( $<30 \mathrm{~mm} \mathrm{SL}$ ) randomly, or in 'runs', in natural aggregations, 212 mussels were removed as an intact clump from a mussel bed in the Menai Strait. In the laboratory one mussel was located 'randomly' by touch and the successive nearest neighbours were pulled out of the clump sequentially and classified as large or small. Departure from a random sequence was assessed using a runs test (Zar 1984).

\section{RESULTS}

When attacking a mussel, a crab first handled it with both chelipeds, turning it through dorso-ventral and anterio-posterior axes. The umbonal region was sometimes held in the right (rarely the left) cheliped as the crab attempted to crush the shell. These unsuccessful attempts persisted for some time and were occasionally interrupted as the crab brought the mussel to the mouthparts. At this stage, the posterior edges of the valves were chipped by the mandibles, but this never led to entry. Eventually the mussel was positioned with the ligament facing outwards and the umbone near the right cheliped. The left cheliped was used to hold the mussel while the crab pressed the propus of the right cheliped against the ligament area. This pressing motion was accompanied by twisting of the propus from side to side. As a result of these movements a small hole was made into which the propus could be inserted. After the propus had penetrated the shell the dactylus was moved up and down in a scissoring movement. Soon the ligament was chipped away, leaving a hole in the shell (Fig. 1). The tips of the chelipeds were then inserted as the crab raised itself and pressed downwards and outward to prise open the mussel. Often, a crab would start feeding on the flesh of a mussel that was only partially opened and in several instances this occurred when the large adductor muscle was still intact. Occasionally, entry was made using similar techniques to bore through the ventral side of the mussel. Preliminary feeding trials showed that the maximum size of mussel that could be opened by shell boring increased with increasing size of the crab up to a shell length of 45 to $50 \mathrm{~mm}$, but larger mussels could not be bored even by the largest crabs (Fig. 2).

When given a choice of 2 sizes, the numbers of crabs taking larger or smaller mussels on the first attack were not significantly different, but on the second attack a significant majority fed on smaller mussels and all subsequent attacks were on smaller mussels (Table 1).

When presented with artificial groups of 4 to 6 mussels, crabs handled most of the mussels before attacking one, usually of the smaller size category. Choices therefore appeared to be based on a comparison of the sizes of mussels available. The mechanism of size assessment remains obscure, but presumably it

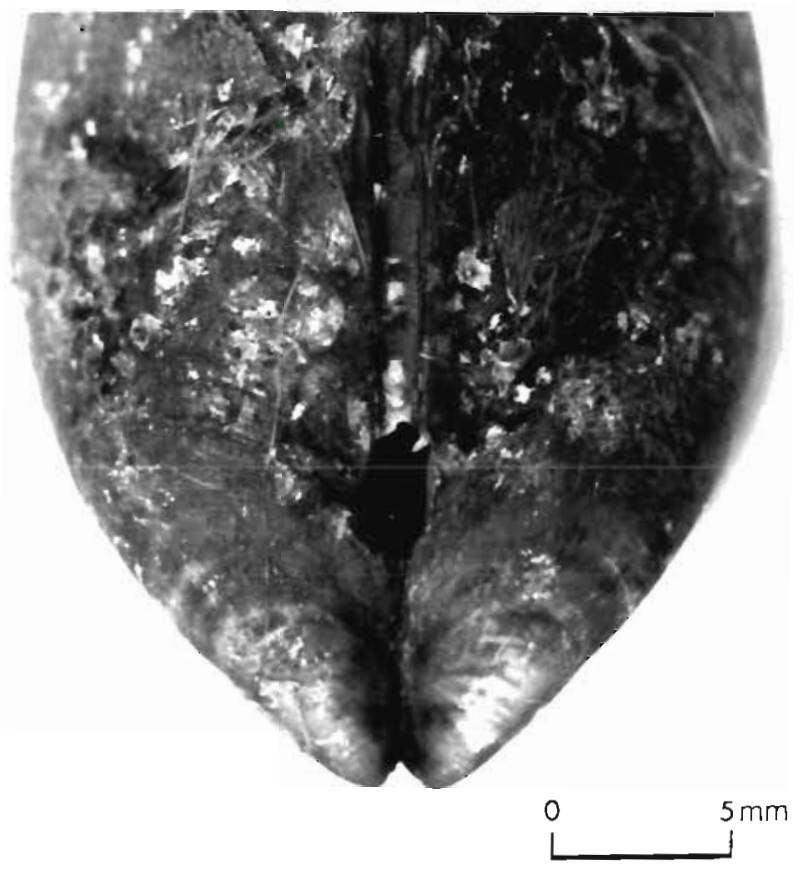

Fig. 1. Mytilus edulis. Hole made by crab Carcinus maenas boring through the ligament of a large mussel 


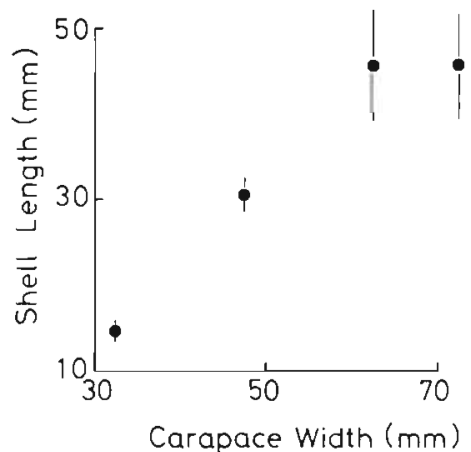

Fig. 2. Mytilus edulis/Carcinus maenas. Maximum size of mussel that can be opened by boring, plotted as a function of crab size. Data are means with standard deviations

Table 1. Carcinas maenas. Pooled data showing the number of large or small mussels Mytilus edulis taken in successive choices. Batch A: twenty $60 \mathrm{~mm} \mathrm{CW}$ crabs presented with 35 $\mathrm{mm}$ (small) and $45 \mathrm{~mm}$ (large) mussels. Batch B: Twenty 65 to $70 \mathrm{~mm} \mathrm{CW}$ crabs presented with $45 \mathrm{~mm}$ (small) and $55 \mathrm{~mm}$ (large) mussels

\begin{tabular}{|lrrrrrrrr|}
\hline \multicolumn{1}{|c}{ Size } & \multicolumn{8}{c|}{ Choice no. } \\
& 1 & 2 & 3 & 4 & 5 & 6 & 7 & 8 \\
\hline Batch A & & & & & & & & \\
Large & 9 & 3 & 2 & 0 & 0 & 0 & 0 & 0 \\
Small & 11 & 17 & 17 & 16 & 7 & 4 & 2 & 1 \\
Batch B & & & & & & & & \\
Large & 13 & 8 & 0 & 0 & 0 & & & \\
Small & 7 & 12 & 19 & 12 & 4 & & & \\
& & & & & & & \\
\hline
\end{tabular}

operates while the crab manipulates the mussel in its chelipeds.

Crabs investigating natural clumps of mussels moved extensively over them, touching mussels in a deliberate manner and sometimes pushing their chelipeds deep into the interstices of the clumps. Having selected mussels, crabs pulled them vigorously with both chelipeds, so breaking the byssus threads. The mussels were then crushed if small enough (10 to $30 \mathrm{~mm}$ SL), or bored if larger. Even though plenty of mussels below the threshold size for crushing were present, crabs always chose some of the larger individuals in addition to the smaller ones. This appeared to happen when, by chance, crabs encountered several large mussels consecutively. The first individuals were rejected but eventually one was attacked. All mussels below the crushing threshold, on the other hand, were attacked as they were encountered.

In the natural clump, mussels tended to be encountered in runs (runs test, $\mathrm{p}<0.01$ ) of mean length 3 , range 1 to 17 , for large mussels and mean length 2 , range 1 to 8 , for small mussels.

\section{DISCUSSION}

Crabs 'bored' into large mussels using a technique similar to that described by Elner (1978). Compared with crushing, boring is a lengthy process and, especially when some of the flesh is left uneaten, yields considerably less energy per unit handling time (Elner \& Hughes 1978). Nevertheless, the total yield from a large mussel is high and if smaller prey are scarce and time is not critical, then it will pay a crab to feed on these prey. This assumes, of course, that the energy used in boring is appreciably less than that gained from the mussel flesh. Crabs respire at about the same rate when handling mussels as they do when crawling about (unpubl. data), so the assumption seems reasonable. Since boring takes 0.5 to $1.5 \mathrm{~h}$ to complete, however, time will become critical in the intertidal zone, where crabs feeding on large mussels might be stranded by the ebbing tide.

Even in sublittoral mussel populations, it might be expected that crabs would always select crushable mussels in preference to larger ones. But in the aquaria crabs took large mussels out of natural clumps with surprising readiness. The explanation of this behaviour may lie in the method used by crabs to assess the optimal diet.

It has been shown that if different prey types are encountered randomly, then in order to maximize its mean net rate of energy intake, a predator should specialize on the most profitable items if these are sufficiently common and ignore or reject less profitable ones (reviewed in Pyke et al. 1978, Hughes 1980). This optimal foraging behaviour relies on predictions being made of encounter rates with different prey types during the foraging bout (Hughes 1979).

If the abundances of the prey remain approximately constant and if the different types of prey are randomly distributed spatially or temporally, then average previous encounter rates will accurately predict those in the immediate future. But this will not be true if different types of prey are patchily distributed, so that when an item of one type is encountered, the next item is more likely to be one of the same type than one of the others. In this case predictions will need to be continually updated as the predator moves among the patches of different prey. In other words, more weight should be given to recent than to more distant experience.

Different sizes of mussels are not randomly mixed in natural mussel beds. A crab encountering a large mussel is quite likely to encounter several of them consecutively and the same would be true for smaller sizes. An 'optimally foraging' crab therefore should base its prediction of encounter rate on the last few mussels handled. All optimally sized mussels should be eaten. Suboptimally sized mussels, however, should be 
rejected at the first encounter but finally accepted if encountered in unbroken sequence, as this would indicate that the crab had moved into a patch of the suboptimally sized prey. Eventual encounter with another optimal prey would revive the bias against the suboptimal prey. Such a behavioural mechanism would explain the tendency of crabs in the present study to attack large mussels encountered in natural clumps while at the same time showing an overall preference for those small enough to be crushed. Similar behaviour was observed by Elner \& Hughes (1978) among crabs given choices of optimal and suboptimal sizes of musseis within the crushable range and is described as the 'runs of bad luck' rule by Krebs \& McCleery (1984). The present data extend this finding to a wider size range of mussels, pertinent to sublittoral populations, and to natural clumps of mussels.

As mussels become larger, the time required to bore into them increases, making them progressively less profitable. Accordingly, crabs in the present study showed an overall preference for smaller mussels to larger ones presented in binary choices (Table 1). This preference, however, was exercised only in presentations subsequent to the first. On the first presentation, crabs attacked smaller and larger mussels with equal frequency. Increased selectivity was probably caused by decreased hunger after the first meal (Jubb et al. 1983).

\section{LITERATURE CITED}

Cunningham, P. N., Hughes, R. N. (1984). Learning of predatory skills by shorecrabs Carcinus maenas feeding on mussels and dogwhelks. Mar. Ecol. Prog. Ser. 16: 21-26

Dare, P. J., Edwards, D. B. (1981). Underwater television observations on the intertidal movements of shore crabs, Carcinus maenas, across a mudflat. J. mar biol. Ass. U.K. 61: $107-116$

EIner, R. W. (1978). The mechanisms of predation by the shore crab, Carcinus maenas (L.), on the edible mussel, Mytilus edulis L. Oecologia (Berl.) 36: 333-344

Elner, R. W., Hughes, R. N. (1978). Energy maximization in the diet of the shore crab, Carcinus maenas. J. Anim. Ecol. 47: 103-116

Hughes, R. N. (1979). Optimal diets under the energy maximization premise: the effects of recognition time and learning. Am. Nat. 113: 209-221

Hughes, R. N. (1980). Optimal foraging theory in the marine context. Oceanogr. mar. Biol. A. Rev. 18: 423-481

Jubb, C. A., Hughes, R. N., ap Rheinallt, J. (1983). Behavioural mechanisms of size-selection by crabs, Carcinus maenas (L.) feeding on mussels Mytilus edulis L. J. exp. mar. Biol. Ecol. 66: 81-87

Krebs, J. R., McCleery, R. H. (1984). Optimization in behavioural ecology. In: Krebs, J, R., Davies, N. B. (ed.) Behavioural ecology: an evolutionary approach. Blackwell Scientific Publications, Oxford, p. 91-121

Naylor, E. (1958). Tidal and diurnal rhythms of locomotory activity in Carcinus maenas (L.). J. exp. Biol. 35: 602-610

Pyke, G. H., Pulliam, H. R., Charnov, E. L. (1977). Optimal foraging: a selective review of theory and tests. $Q$. Rev. Biol. 52: 137-154

Seed, R. (1969). The ecology of Mytilus edulis L. (Lamellibranchiata) on exposed rocky shores. II. Growth and mortality. Oecologia (Berl.) 3: 317-350

Zar, J. H. (1974). Biostatistical analysis. Prentice-Hall Inc., Englewood Cliffs, New Jersey

This article was submitted to the editor; it was accepted for printing on March 5, 1987 